
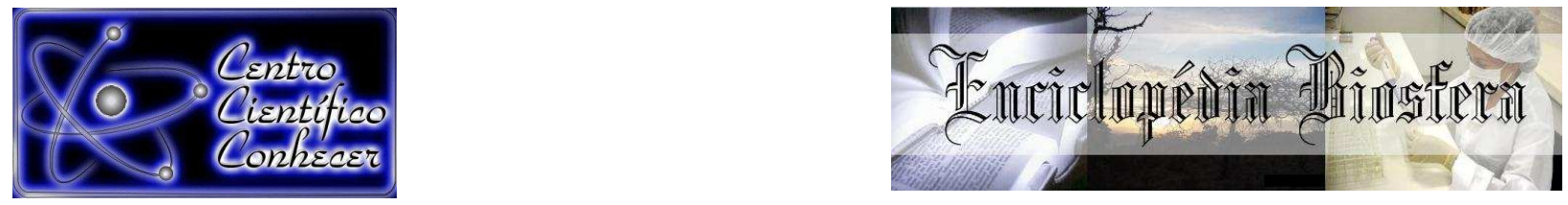

\title{
CARACTERIZAÇÃO SÓCIO CULTURAL E EDUCACIONAL DE PROJETOS DE ASSENTAMENTO NO MUNICÍPIO DE MOJU, PARÁ
}

Clenes Cunha Lima1 ${ }^{1}$ Irlene Farias Pereira de França², Ailton Souza Silveira ${ }^{3}$

1 Professora Mestre em Ciências Florestais, Universidade Federal Rural da Amazônia (clenes.cunha@ufra.edu.br) Pará-Brasil

2 Pedagoga Especialista em Psicopedagogia pela Faculdade Ipiranga, Pará 3 Zootecnista na Empresa de Assistência Técnica e Extensão Rural do Estado do Pará (EMATER/PA)

Recebido em: 08/04/2016 - Aprovado em: 30/05/2016 - Publicado em: 20/06/2016 DOI: 10.18677/Enciclopedia_Biosfera_2016_026

\begin{abstract}
RESUMO
Este trabalho tem por objetivo diagnosticar o perfil sociocultural e educacional das famílias agricultoras assentadas nos projetos de assentamento Maravilha e Vale do Moju, município de Moju, Pará. Para levantamento das informações foram realizadas entrevistas individuais in loco em questionário fechado e atividades coletivas junto às famílias residentes nos PA's. Para o trabalho com os dados foram adotados procedimentos descritivos e analíticos, articulando os aspectos quantitativos com os qualitativos. Diante do cenário identificado nos PA's e das necessidades apontadas pelas famílias, necessário se faz, enquanto mitigador das condicionantes, que ações sociais sejam criadas ou reestruturadas, contribuindo com uma maior interação entre os próprios moradores, bem como favorecendo atuação em causas mais específicas e emergenciais, tais como, melhorias no nível educacional, saneamento básico e saúde.
\end{abstract}

PALAVRAS-CHAVE: agricultor familiar, diagnóstico, organização social

\section{CHARACTERIZATION SOCIO CULTURAL AND EDUCATIONAL PROJECTS TO FIXING THE MUNICIPALITY MOJU, PARÁ}

\begin{abstract}
This study aims to diagnose the socio-cultural and educational profile of the farming families settled in settlement projects and Wonder Valley Moju, municipality of Moju, Para. To survey the information was held individual interviews on the spot closed questionnaire and group activities with families residents of PA's. To work with the data descriptive and analytical procedures were adopted, linking the quantitative aspects with the qualitative. Given the scenario identified in the PA's and needs identified by families, need to do, while mitigating the constraints that social actions are created or restructured, contributing to greater interaction between the residents and encouraging performance in more specific and emergency causes such as improvements in schooling, sanitation and health.
\end{abstract}

KEYWORDS: diagnosis, family farmers, social organization

ENCICLOPÉDIA BIOSFERA, Centro Científico Conhecer - Goiânia, v.13 n.23; p. 289 


\section{INTRODUÇÃO}

$\mathrm{Na}$ região do Baixo Tocantins, o processo de organização social está relacionado aos enfrentamentos de desafios, tais como: luta pela terra, reivindicação de crédito, assistência técnica para a produção, melhoria da infraestrutura (estradas e eletrificação), garantia dos serviços sociais básicos (educação, saúde e transporte), sendo que tais lutas forjaram a existência de uma diversidade de organizações, instituições sociais e movimentos reivindicatórios (PTDRS, 2011).

Os direitos sociais objetivam garantir aos indivíduos condições materiais tidas como imprescindíveis para o pleno gozo dos seus direitos, para isso a sociedade tende a exigir do Estado intervenções para manter a ordem e diminuir as desigualdades sociais. As ações para construção da cidadania devem iniciar com a emissão da certidão de nascimento e dos demais documentos de identificação, posteriormente por meio de acesso aos serviços sociais básicos (PESSOA, 2011).

Segundo SANTOS JUNIOR (2011), não se pode prever o efeito das políticas públicas em virtude das variáveis e efeitos emergentes, e enfatiza que a "não realização" desta não quer dizer neutralidade, mas sim o indicativo de que as ações devem ser planejadas e melhoradas. As políticas públicas direcionadas ao homem do campo são incipientes e/ou inexistentes, em geral são implantadas esporadicamente, consequentemente não atendem às necessidades das famílias.

A efetividade dos direitos econômicos e sociais em cada país depende em grande parte da adoção de múltiplas e variadas medidas complementares, na maioria dos casos de caráter promocional, em todos os campos de ação: político, jurídico, social, econômico, cultural, sanitário, tecnológico, etc. ROMERO (2014), destaca que a situação de pobreza e ausência de renda, se molda a partir da deficiência de políticas públicas e serviços básicos.

Entre os bens produzidos pela sociedade e, que precisam ser disponibilizados para a classe trabalhadora e, principalmente para os trabalhadores rurais sem terra, está à educação (NETO \& BEZERRA, 2007). Estes autores destacam, porém, que não basta praticar qualquer tipo de educação. A educação considerada ideal deve estar voltada para o homem do campo, fazendo com que este compreenda as causas de sua miséria e os mecanismos de dominação utilizados pela elite dominante do país.

Ao se discutir educação, MOREIRA (2015) enfatiza que não se pode perder de vista que esta ocupa lugar central na acepção coletiva da cidadania, considerando que ela se constrói no processo de luta que é em si própria, um movimento educativo.

Esta autora destaca a educação como um instrumento indispensável para o exercício da cidadania, a educação, no caso específico dos assentamentos rurais e das comunidades rurais, ganha uma importância ainda maior, uma vez que toda a vida social (familiar e comunitária) e produtiva acontece num ambiente particular, não apenas pelas dimensões físicas que o envolvem, mas também pela dimensão política que assume.

FRIGOTTO (2011) destaca que a educação e pedagogia do campo, parte-se da particularidade e singularidade dadas pela realidade de homens e mulheres que produzem suas vidas no campo. Entretanto, não se postula o localismo e nem o particularismo, mediante os quais se nega o acesso e a construção do conhecimento 
e de uma universalidade histórica e rica, porque é a síntese do diálogo e da construção de todos os espaços onde os seres humanos produzem sua vida.

Historicamente, os trabalhadores têm tido dificuldade de acessar os seus direitos garantidos pelo Estado e ficam desprotegidos dos riscos que envolvam a saúde, a previdência social e a assistência social. Mobilizados pela forma desigual e contraditória na concessão dos direitos sociais, os trabalhadores vêm inserindo-se, no decorrer da história, num processo de construção de seus direitos, momentos permeados de conflitos e lutas pela posse da terra, pela sobrevivência e por melhores condições de vida (SCHLINDWEIN, 2011).

Alguns autores destacam que a caracterização dos aspectos socioeducacionais e culturais de comunidades rurais tornam-se particularmente importante em função da aferição da situação social dos trabalhadores rurais e da comunidade como um todo, além de incidir num diagnóstico que embase a implementação de políticas públicas direcionadas, em especial, para a manutenção das atividades de geração de renda e inserção de outras, bem como contribuir para a melhoria da qualidade de vida da população (TERCEIRO et al. 2013; ALVES et al. 2015).

Neste contexto, este trabalho tem por objetivo analisar e discutir os aspectos sociocultural e educacional dos Projetos de Assentamento Maravilha e Vale do Moju, localizados no município de Moju, Pará.

\section{MATERIAL E MÉTODOS}

O projeto de Assentamento Maravilha compreende uma área de 8.713 ha localizado nos municípios de Tailândia e Moju, obtidos através do Processo de Compra e Venda e Desapropriação dos imóveis denominados "Fazendas Moju-açú, Maravilha, Cruzeiros do sul e Moju-mirim", com área registrada de 8.650,6734 ha. 0 PA está localizado a oeste do município de Tailândia e a leste do município de Moju, localizados na Mesorregião Nordeste Paraense e à Microrregião homogênea de Tomé-açú, perfaz-se o acesso principal pela PA 150 a cerca de $2 \mathrm{~km}$ da sede do município de Tailândia em direção a Moju, com acesso secundário pelas vicinais 04 , 06, 08 e 10, percorrendo-se ainda, mais 14 a $16 \mathrm{~km}$ de ramais de terra batida dentro do assentamento no sentido do Rio Moju.

O Projeto de Assentamento Vale do Moju possui uma área delimitada total de 21.357,1324 ha dividido em 400 parcelas individuais. O PA é cortado, no sentido oeste-leste (Tailândia-Moju), por diversas vicinais. O acesso ao PA se dá tanto por via terrestre como por via fluvial. O principal acesso ocorre por via terrestre feito pela Rodovia Estadual PA-150, pavimentada e de tráfego permanente, a partir de quatro vicinais (Vicinal 4, 6, 12 e vicinal Nova Paz).

Ambos os PA's, possuem um espaço destinado a implantação de infraestruturas de caráter coletivo, como é o caso de algumas já existentes, como: escola, igreja, sede da associação, campo de futebol. As estradas e ramais constituem-se como as demais infraestruturas coletivas existentes nos PA's.

As coordenadas geográficas dos municípios de Moju e Tailândia, são, respectivamente, $01^{\circ}$ 53' 10" de latitude Sul (“-1.8847) e 4846” $00^{\prime \prime}$ de longitude (48.7652) a Oeste de Greenwich; e 02.55,37 S de latitude Sul e 49.04,12 de longitude a Oeste de Greenwich (IBGE, 2010). 
Esta pesquisa foi operacionalizada através de um enfoque participativo e democrático. Para tanto, foi utilizado um caminho metodológico, com uso de várias ferramentas e técnicas de pesquisa capazes de responder aos objetivos de elaboração deste Plano, assegurando a tomada de decisão por parte das famílias assentadas. Todo esse processo culminou na coleta, tabulação análise e sistematização deste documento.

Ocorreram entrevistas semiestruturadas realizadas in loco, através da realização de visitas lote a lote para aplicação do questionário, preenchendo-o conforme as respostas dadas por cada entrevistado, sendo este o proprietário do lote (na grande maioria dos casos) ou seu representante (cônjuge ou filhos). A condução da pesquisa foi baseada segundo os critérios básicos preconizados por VERDEJO (2006), no Diagnóstico Rural Participativo, sobre entrevistas semiestruturadas, no qual abrange que as entrevistas podem ser realizadas com pessoas chaves ou com grupos.

O resultado do levantamento totalizou em 147 famílias entrevistadas no PA Maravilha e 377 famílias entrevistadas no PA Vale do Moju. Na construção deste trabalho contou-se com 0 apoio das lideranças locais, em especial de representantes legais dos assentados (membros da diretoria das associações dos PA's), que colaboraram na mobilização, agendamento das visitas juntos aos moradores, localização dos lotes/propriedades e apoio logístico a equipe de trabalho, além de moradores mais antigos que colaboraram como informantes chaves para a aplicação dos questionários com questões abertas referentes ao PA.

Também foram realizadas oficinas de autodiagnostico de forma coletiva, abordando as temáticas sociocultural e educacional, desenvolvidas através da aplicação de diversas metodologias participativas, tais como: Linha do Tempo, Diagrama de Venn, Matriz de Peso, Rotina Diária das Famílias, Mapa Falado, Painel Interativo e Mapa dos Recursos Naturais, o que assegurou uma participação efetiva dos assentados.

O tratamento dos dados coletados ocorreu através da tabulação e organização destes, seguida da análise e sistematização escrita. Para o trabalho com os dados foram adotados procedimentos descritivos e analíticos, articulando os aspectos quantitativos com os qualitativos, procurando garantir a veracidade das informações coletadas.

\section{RESULTADOS E DISCUSSÕES}

A História de criação dos PA's Maravilha e Vale do Moju tem características semelhantes aos processos vivenciados por vários PA's da região sul e sudeste do Pará quanto à regularização fundiária, que se deu a partir do processo de ocupação de terras (fazendas) por agricultores.

Em relação ao processo de conquista da área pelos assentados, verifica-se que no decorrer destes anos as famílias adquiriram o lote por meio do processo de Reforma Agrária, onde conquistaram suas áreas principalmente pelo processo de compra da propriedade rural $(74,3 \%)$, através de recibos de compra e venda; seguidos por concessão de uso $(20,9 \%)$ e finalizando com a conquista da propriedade realizada através de herança $(4,9 \%)$. Neste sentido, os agricultores não se consideravam posseiros, mas sim compradores de lotes de terra. 
Entre tantas concepções, SOUZA (1995), enfatiza que os grupos sociais passam a lutar pela apropriação de um espaço e, sobretudo pelos recursos naturais, principalmente a terra para que nela possa desenvolver a sua função social.

Quanto à origem dos assentados, a predominância populacional estava relacionada aos Estados do Pará e Maranhão, com percentuais 44,0\% e 18,0\% respectivamente, conforme demonstrado na Figura 1.

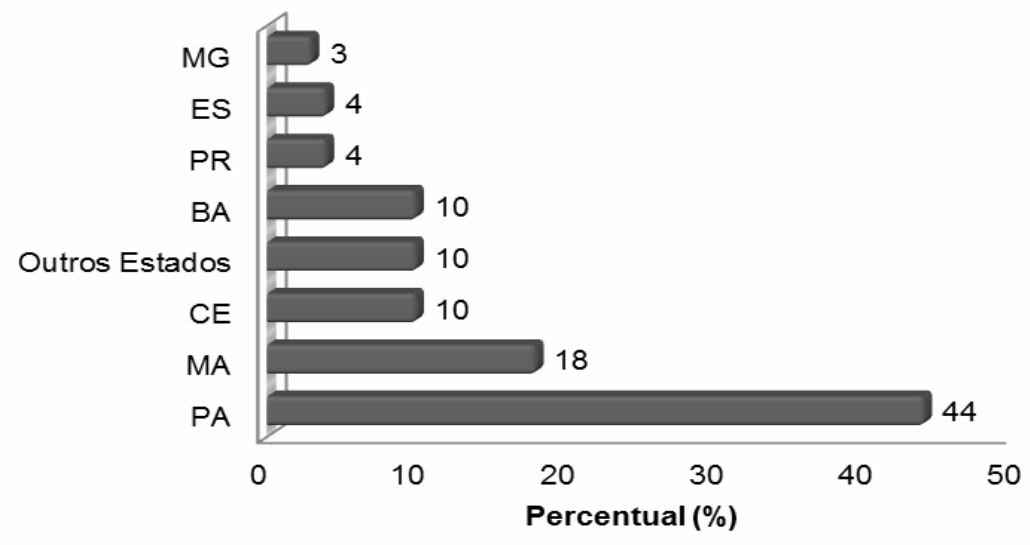

FIGURA 1 Distribuição dos Estados de origem dos assentados dos PA's Maravilha e Vale do Moju. Fonte: EMATER/PA, Esloc Tailândia, ano base 2012.

Verifica-se como potencialidade no foco social, o fato da maioria dos assentados terem sua origem no Estado do Pará, com isso, ter maiores conhecimentos sobre a região específica. No entanto, pode-se considerar que este cenário retrata uma relevante importância do fenômeno migratório que tem ocorrido em várias regiões do país, com os movimentos populacionais acompanhados pela expansão da fronteira agrícola. Tal fato é evidenciado por FRANCO \& LIMA (2008), onde destacam que a mobilidade espacial da população rural está relacionada com a busca de melhores condições de vida, oportunidades de sobrevivência que muitas vezes não contempladas no local de origem, originando um tipo de exclusão social, que incita novos deslocamentos humanos num contexto rural-urbano e vice-versa.

Conforme análise de dados relativos à distribuição da faixa etária dos integrantes dos PA's (Figura 2), a população adulta apresentou-se mais expressiva que as demais faixas etárias analisadas. Estes dados confirmam a realidade no âmbito da agricultura familiar. Do quantitativo pesquisado o universo amostral foi de 1.369 residentes no PA Vale do Moju, distribuídos nas 377 famílias e 621 residentes no PA Maravilha, distribuídos nas 147 famílias, com uma média de três a quatro pessoas por família. 


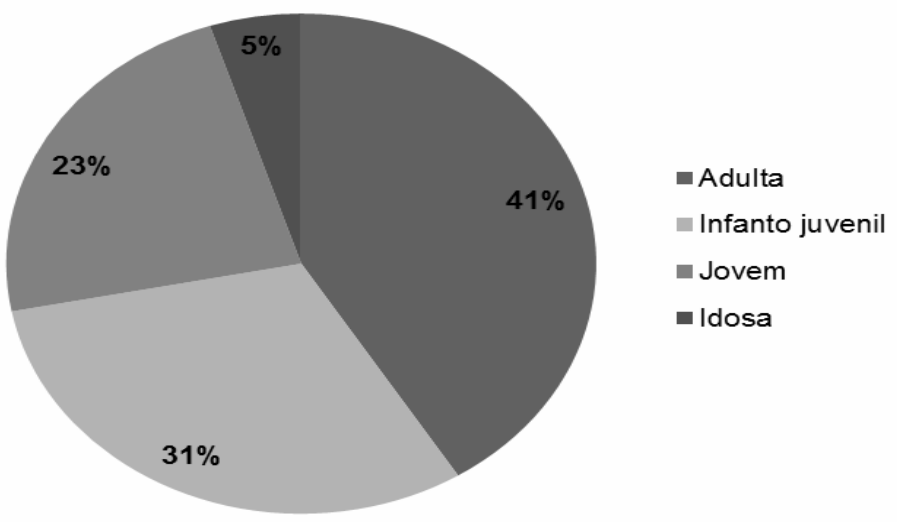

FIGURA 2 Distribuição da faixa etária dos moradores assentados nos PA's Maravilha e Vale do Moju. Fonte: EMATER/PA, Esloc Tailândia, ano base 2012

O fato da população adulta e infanto- juvenil apresentarem os maiores públicos, respectivamente, expressando uma população jovem, requer uma necessidade iminente de maiores incentivos e investimentos dentro dos assentamentos, priorizando-se infraestrutura, saúde e educação para esta população jovem.

Para CAMARANO (2002), mesmo existindo o entendimento de que existem maneiras diferentes de perceber a velhice a partir de critérios socioculturais e econômicos, a utilização do critério etário acaba prevalecendo justamente pela dificuldade em se estabelecer um critério universal. Logo, o diagnóstico sobre a faixa etária de comunidades rurais, é um critério para identificar o grau de envelhecimento destas comunidades.

No entanto, para este mesmo autor, deve-se haver o entendimento de que o envelhecimento também leva em conta as variações culturais, que neste caso refere-se a processos biológicos, aparência física, eventos de desengajamento da vida social, como aposentadoria, e o aparecimento de novos papéis, como o de avós.

Ao considerar a divisão da população quanto ao gênero familiar o percentual correspondente ao gênero masculino é de $55,6 \%$ e para o gênero feminino de $44,4 \%$, sendo a exceção dessa predominância evidenciada somente na faixa etária compreendida dos sete aos dez anos de idade. Em se tratando dos titulares dos lotes, $69,2 \%$ são homens. Esta é uma realidade que faz parte da reforma agrária, onde os homens têm mais acesso a terra que as mulheres.

Em relação ao estado civil dos assentados, identificou-se que o maior percentual encontra-se entre os amasiados $(41,0 \%)$. Ao considerar o percentual de assentados que compartilha a gestão do lote (casados e amasiados) este é superior $(68,4 \%)$ ao percentual referente aos titulares que em tese gerenciam seus estabelecimentos rurais de forma individual (solteiros, divorciados e viúvos) se considerar que a maioria dos lotes é constituída por famílias extensas.

O tempo de moradia analisado foi na faixa temporal de cinco anos de residência, onde identificou-se que, o maior quantitativo informado sobre o tempo de 
residência ficou compreendido na faixa de oito anos, com 41,9\%, conforme visualizado na Figura 3.

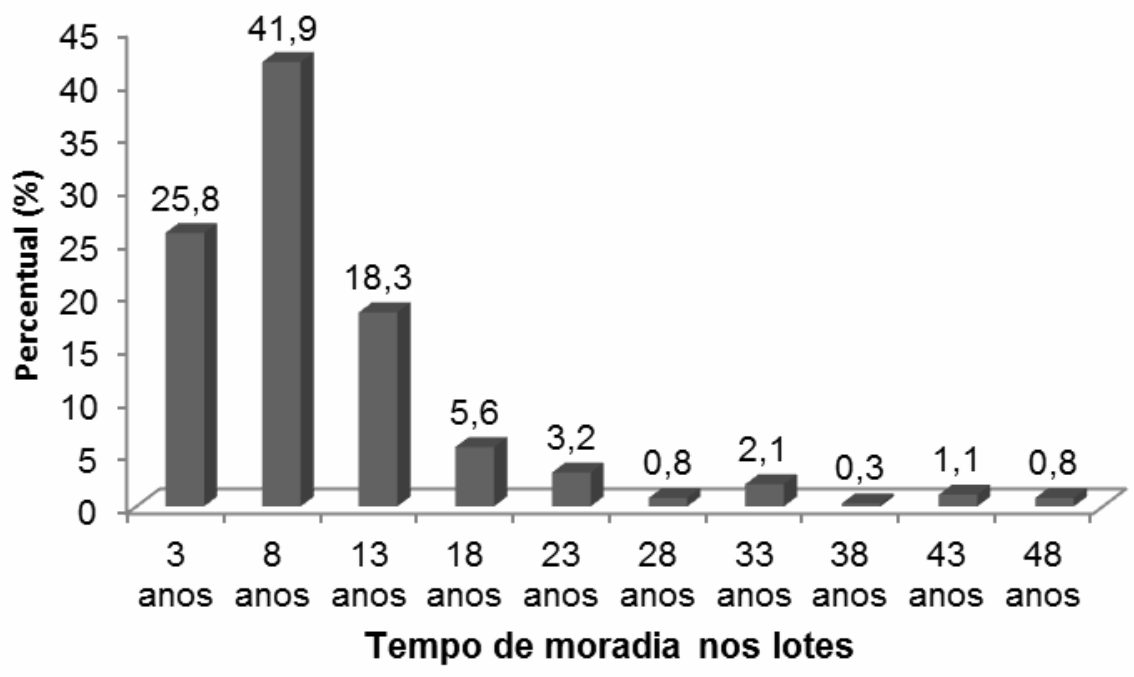

FIGURA 3 Tempo de moradia dos assentados do PA Vale do Moju no ano de 2012. Fonte: EMATER/PA, Esloc Tailândia, ano base 2012.

Verifica-se, portanto, que a população residente nos PA's em questão, constitui-se por tempo de ocupação de área e moradia recentes, ao considerar-se o percentual de $86,0 \%$ correspondente ao período de 3 a 13 anos. No PA Maravilha foi constatado que existe uma organização interna dos assentados estruturada através da Associação dos Moradores Unidos do Projeto de Assentamento Maravilha do Município de Tailândia - ASMUPAMTA. No PA Vale do Moju a organização social ocorre através de duas associações: Associação dos Mini e Pequenos Produtores Rurais da Vila Nova Olinda do Assentamento Vale do Moju - AMPROVNOAVM; e Associação dos Agricultores Nova Esperança do Projeto de Assentamento Vale do Moju - AGRINEPAVAM.

Segundo os representantes das associações, de forma geral, o principal objetivo das mesmas foi buscar melhorias para seus associados e benfeitorias para o próprio assentamento visando a implementação dos serviços sociais básicos voltados ao atendimento da coletividade, como crédito, educação, saúde, e outros.

Ao entrevistar os assentados titulares dos lotes, verificou-se que 53,9\% participam das organizações sociais e 46,1\% não participam. Ao transpor esta mesma análise para o público de cônjuges, verificou-se a redução do percentual de participação desta categoria em grupos sociais $(37,2 \%)$.

Esta análise referente à participação em grupos sociais considerou a participação dos titulares dos lotes juntamente com seus cônjuges em instituições como: associações, cooperativas, grupos de jovens, grupo de mulheres, Organizações Não Governamentais, Sindicato dos Trabalhadores e Trabalhadoras Rurais, entre outras.

Vale ressaltar que a organização dos agricultores familiares apesar de existente, precisa ser revitalizada, para potencializar a seu legitimo valor representativo junto a coletividade. Para 0 alcance do fortalecimento do 
desenvolvimento organizacional dos PA's deverão ser realizadas para os assentados cursos, treinamentos, oficinas e palestras sobre associativismo e cooperativismo, uma vez que ações sociais que favoreçam a criação ou reestruturação de grupos sociais no assentamento, constituem-se de elevado potencial na interação entre os próprios moradores, bem como favorecendo atuação em causas mais específicas.

Ao considerar os apontamentos de NABOZNY \& RODRIGUES (2011) e BORIN \& LIMA (2013), pode-se ressaltar a carência na organização social dessas comunidades, considerando que houve baixa atuação e articulação entre os membros comunitários nas associações vigentes nas comunidades. Tal fato pode ser observado entre os membros dos PA's em estudo, no qual houve pouca participação das famílias assentadas nas organizações sociais dos PA's e dos municípios aos quais fazem parte.

Este cenário coincide com às ideias baseadas no associativismo, que conforme SENAR (2011), uma associação legalmente registrada possibilita a seus associados ter voz e se fazer ouvir na sociedade e nos espaços de decisão pública, como os conselhos municipais de desenvolvimento rural sustentável, de educação, de saúde, de segurança, de meio ambiente, entre outros. Da mesma forma, para representar os seus interesses em câmaras municipais, em políticas e programas governamentais, ou mesmo para obterem acesso a algumas linhas de crédito, os produtores e trabalhadores rurais necessitam se organizar.

Devido à importância do setor agrícola a nível regional, necessário se faz a adoção de enfoques inovadores na agricultura como 0 fortalecimento da organização social do agricultor familiar, cooperação entre os associados e estímulos à competitividade visando o estabelecimento de economias regionais seguras, independentes e autossuficientes (BRASIL, 2012).

Quanto ao recebimento de benefícios sociais, 60,0\% dos assentados não tem acesso a nenhum beneficio social e 40,2\% dos assentados obtiveram rendas oriundas de tais benefícios, segmentados em aposentadorias (por idade e por invalidez), bolsa família e seguro defeso. Tem-se, portanto, um percentual expressivo de assentados que não recebem benefícios sociais, apesar dos PA's encontrarem-se próximos ao perímetro urbano do município de Tailândia.

Dentre os benefícios sociais recebidos pelos assentados, o programa Bolsa família é o que se apresenta de forma mais significativa $(76,7 \%)$, com a inserção de recursos mínimos de $R \$ 30,00$ e máximos de $R \$ 600,00$ por família beneficiária analisada. Da totalidade dos titulares (524 incluindo os dois PA's), 90,1\% designamse como agricultores familiares. Percentual este mais elevado que o percentual referente à ocupação com agricultura familiar exercida pelos moradores dos PA's em períodos anteriores à fixação de moradia em seus lotes atuais.

Quanto à ocupação anterior dos moradores assentados, verificou-se que a maioria $(73,2 \%)$ era agricultor familiar; $8,4 \%$ da totalidade desenvolviam outras atividades (como artesãos, caminhoneiros, mecânicos e operadores de máquinas) e $4,2 \%$ ocupavam-se de outras atividades rurais (como trabalhadores rurais, extrativistas e pecuaristas).

Ao analisar a escolaridade dos assentados dos PA's, constatou-se que a maior percentagem $(67,0 \%)$ encontrava-se no ensino fundamental (completo e incompleto), seguida de $12,4 \%$ da população com educação infantil ou alfabetizada; 
$11,4 \%$ com ensino médio (completo e incompleto) $8,1 \%$ de analfabetos e $1,0 \%$ da população com nível superior (completo e incompleto).

Ao relacionar a escolaridade em relação ao gênero dos integrantes dos PA's, verificou-se a seguinte discriminação: i. o percentual de analfabetos é menor entre as mulheres $(6,9 \%)$ do que em relação aos homens $(9,1 \%)$; ii. ao considerar o percentual de pessoas alfabetizadas, a população masculina possui índices maiores $(13,4 \%)$ em relação a feminina $(11,2 \%)$; iii. ao considerar os ensinos fundamental, médio e superior, a população feminina apresentou maiores índices $(68,6 ; 11,6$ e $1,6 \%$ respectivamente) de escolaridade em relação a população masculina $(65,8$; 11,2 e $0,6 \%$, respectivamente).

De modo geral, conforme PINHEIRO (2011), a educação do campo tem se caracterizado como um espaço de precariedade por descasos, especialmente pela ausência de políticas públicas para as populações que lá residem. Essa situação tem repercutido nesta realidade social, na ausência de estradas apropriadas para escoamento da produção; na falta de atendimento adequado à saúde; na falta de assistência técnica; no não acesso à educação básica e superior de qualidade, entre outros.

É importante considerar os apontamentos de FERREIRA \& BRANDÃO (2011), que destacam que a educação em assentamentos e acampamentos, desde o início do Movimento dos Trabalhadores Rurais Sem Terra, foi realizada de diferentes formas e de acordo com as possibilidades estruturais e conjunturais, pois não dispunham de infraestrutura mínima para ensinar nas escolas em barracos cobertos de lonas, com bancos de madeira ou sentadas no chão ou mesmo sob as sombras das árvores.

Ao analisar o serviço social de saúde pública ofertado aos assentados, este se apresenta com elevada deficiência, visto que não há postos de atendimentos nos projetos de assentamento e as visitas de agentes comunitários de Saúde - ACS expressam um reduzido percentual $(15,8 \%)$ em relação à necessidade da totalidade das famílias.

Quando necessitam de serviços hospitalares as famílias assentadas recorrem às sedes municipais da região do Baixo Tocantins (como Tailândia, Moju e Goianésia do Pará) ou à capital paraense, Belém, bem como a outras capitais, dependendo do tipo de doença a ser tratada, da gravidade da enfermidade, do acesso logístico nessas cidades entre outras situações ímpares.

A escolha da cidade a que recorrem aos serviços médicos está relacionada a fatores diversos, em alguns casos o fato de ter parentes residentes na mesma que possa dar apoio logístico, em outros a gravidade da doença é o fator determinante para busca de serviços mais especializados.

Quando há ocorrência de enfermidades diversas nos assentamentos, os moradores costumam em sua maioria procurar ajuda profissional, com tratamentos médicos, e em menor escala, utilizam a automedicação e os serviços de benzedeiras. A automedicação deve-se basicamente ao tratamento de doenças consideradas mais comuns, como gripes e resfriados. As maiores ocorrências de doenças nos PA's referem-se à verminose (14,8\%), doenças respiratórias $(13,1 \%)$ em especial viroses e malária (12,9\%).

O saneamento básico é precário, pois não há nenhum serviço público referente à coleta de lixo ou de orientação quanto ao manuseio, coleta seletiva e 
destinação do mesmo, considerando que aproximadamente 96,0\% dos estabelecimentos rurais adotam a queima do lixo como descarte. Diante deste cenário, necessário se faz a orientação dos agricultores familiares para que estes possam aproveitar melhor estes resíduos, separando-os em orgânicos e inorgânicos e os aproveitando em reciclagens, além de elaboração de compostos orgânicos, contribuindo assim com ações de melhoria ao meio ambiente e à saúde humana.

De modo geral o lixo é um dos graves problemas que afeta a sociedade moderna, e as comunidades rurais de modo particular, visto que quando ele não é tratado adequadamente, e/ou não seja depositado em locais apropriados ou realizada sua coleta gera várias consequências como a contaminação do solo, ar, água, doenças, degradação do meio ambiente, entre outras (CONSUMO SUSTENTÁVEL/MANUAL DE EDUCAÇÃO, 2005).

Quanto às instalações sanitárias existentes nas propriedades rurais, estas se apresentam bastante diversificadas. Dos tipos de instalações citadas, a utilização de buracos escavados no chão, com a construção de paredes ao redor dos respectivos buracos, corresponde ao maior percentual de utilização $(34,1 \%)$, seguido pela realização das necessidades físicas e biológicas a céu aberto $(28,2 \%)$, mostrandose, portanto, como saneamento básico inadequado ou precário na maioria das residências analisadas.

Essa é uma questão preocupante, haja vista a grande ocorrência de doenças relacionadas a estes, pois segundo o MANUAL DE SANEAMENTO RURAL (2006), são basicamente duas portas de entrada do agente infeccioso no organismo humano: a boca e a pele. Portanto, o melhoramento das instalações, bem como a realização de atividades educativas voltadas para a questão sanitária são elementos que se colocam como importantes para a melhoria da qualidade de vida dos agricultores assentados.

Quanto à procedência e a qualidade da água utilizada para o consumo humano dentro do assentamento, coletou-se informações que indicam que as fontes de água utilizadas pelas famílias são diversas, como: poço amazônico, igarapé, cacimba (nascentes ou brotações de água), dentre outras, sendo que a grande maioria, 37,8\% faz uso de água proveniente do igarapé e 30,2\% utilizam água de poços amazônicos e apenas $0,3 \%$ detêm a utilização através de sistemas de água encanada.

Quanto ao tratamento da água adotado pelas famílias observou-se que este é bastante variado (coação, fervura, filtração, hipocloração e nenhum). Nesta análise, ressalta-se o percentual significativo de $12,4 \%$ de pessoas que informaram não realizar qualquer tipo de tratamento na água a ser consumida.

Estas informações demonstram que nos PA's Maravilha e Vale do Moju as famílias assentadas já apresentam algum grau de conscientização acerca da realização de tratamentos da água a ser consumida. Mesmo assim torna-se necessário a intervenção dos profissionais da saúde para desenvolverem ações educativas e preventivas, fazendo com que um maior número de pessoas passe a utilizar métodos seguros de prevenção contra doenças.

De acordo com a Organização Mundial de Saúde - OMS, atenção primária em saúde - APS são ações desenvolvidas por profissionais de saúde que disponibilizam serviços às comunidades em diferentes níveis, desde visitas domiciliares até 
reuniões inter-setoriais, perpassando por serviços de vacinação, reuniões com a comunidade, dentre outras ações (BRASIL, 2010).

Ao sistematizar os dados oriundos das entrevistas realizadas com os assentados, verificou-se que, no assentamento não há o programa de Atenção Primária em Saúde, como também não há o exercício do Programa Saúde da Família - PSF, tornando-se, portanto mais deficitário o atendimento de saúde aos agricultores assentados no PA Maravilha e Vale do Moju.

Nota-se também a presença de fatores relacionados à saúde humana, tais como o alcoolismo, que embora seja considerado reduzido no assentamento $(4,09 \%)$, de certa forma interfere no bem estar social dos assentados, bem como pode vir causar problemas comprometedores de ordem social nos PA's.

As famílias entrevistadas mostraram pouca identificação com a sociabilidade advinda das práticas de lazer, tendo sua vida social pouco organizada em torno da comunidade, conforme se observa na Figura 4.

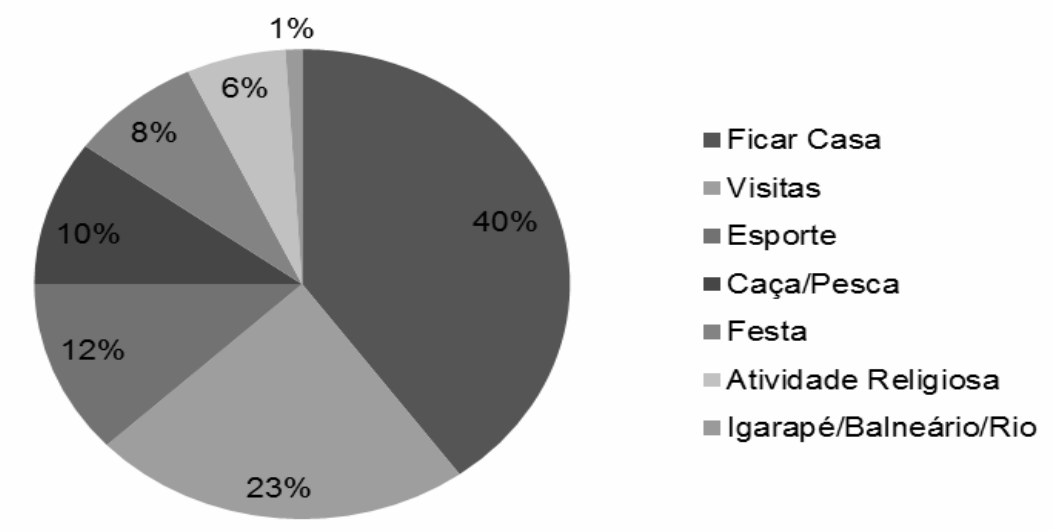

FIGURA 4 Práticas de Lazer das famílias assentadas no

PA Maravilha e Vale do Moju. Fonte:

EMATER/PA, Esloc Tailândia, ano base 2012

A maioria dos assentados considerou a prática "ficar em casa" (40\%) como forma de lazer, ou seja, aqui caracterizada como a realização de atividades póstarefas da propriedade. A realização de visitas foi identificada por $23 \%$ dos assentados, seja em casa de parentes e/ou amigos, porém esta prática está mais voltada no interesse social de relacionamento, do que numa prática de lazer propriamente dita. No entanto, se tal prática causa bem estar ao individuo, já é considerada como quebra de rotina e esta desempenha a função social da unidade familiar.

Apesar de ser citado por apenas $12 \%$ dos proprietários de lotes durante a aplicação dos questionários, a prática de esporte é comum nas famílias dos PA's, podendo ser confirmado pela existência de vários campos de futebol distribuídos nas agrovilas dos PA's.

Para as práticas de caça/pesca, festas e atividade religiosa são consideradas e praticadas por 10, 8 e $6 \%$ dos indivíduos, respectivamente. A caça/pesca está direcionada para a subsistência das famílias. Quanto às atividades religiosas, pode-se dizer que são constantes, tendo em vista a existência de três 
igrejas católicas e três evangélicas distribuídas nas agrovilas do PA Vale do Moju e três igrejas evangélicas e uma católica no PA Maravilha.

Houve um baixo índice para igarapés/balneários/rios enquanto prática de lazer, com uma representatividade de $1,0 \%$ dos entrevistados. Isso demonstra a baixa relação do lazer com o ambiente e os recursos naturais. Tal fato pode estar relacionado pela abundância destes recursos existentes principalmente no PA Vale do Moju, nas vilas Amorim, Curuçá e Timboteua e, portanto, torna-se não um lazer das famílias, mas sim uma rotina diária, que envolve a realização de afazeres domésticos, como lavar louças e roupas.

De uma forma geral, os resultados obtidos para as práticas de lazer desenvolvidas pelos assentados dos dois PA's, demonstram uma baixa funcionalidade do lazer enquanto divertimento e recreação proporcionados por estas atividades.

WEIDUSCHADT (2009) discute a fragmentação entre trabalho e lazer, no contexto do cotidiano da comunidade, onde no campo é percebida uma separação muito tênue, onde especifica que isto possa ser porque o trabalho ligado à agricultura não apareça de forma tão explícita a dicotomia entre tempo de trabalho e tempo de lazer. Assim, o tempo de trabalho e de não trabalho parece estar junto, no sentido que as principais manifestações de lazer desta comunidade possam parecer estar atreladas ao trabalho.

As manifestações festivas e de grupos sociais que são realizadas nos PA's, são em suma advindas das programações religiosas. Embora existam no município de Moju muitas manifestações, desde as religiosas até a cultura popular local, como as organizadas pelo grupo folclórico de Boi-bumbá, o agricultor assentado dos PA's Maravilha e Vale do Moju, se desloca para Tailândia quando ocorrem às festividades neste município, seja para participar destes eventos, seja para aproveitar feriados para desenvolvimento de atividades particulares.

A característica da cultura pouco marcante nos PA's Maravilha e Vale do Moju, pode ser decorrente das trajetórias culturais diferenciadas desta comunidade, uma vez que os assentados tem origem de diferentes estados do Brasil. ALVES et al. (2015) destacam que as ações educativas poderiam ser implementadas, na finalidade de incentivar os jovens e interessados às atividades culturais, até mesmo como forma de angariar recursos financeiros e manter a tradição local, assim como medidas políticas destinadas as famílias para melhoria das condições de vida e de trabalho por meio do acesso facilitado aos direitos trabalhistas da classe.

WEIDUSCHADT (2009), atenta que, ao analisar o grupo e as relações sociais com seus valores e manifestações, é necessário levar em consideração que as lembranças e imagens dos sujeitos estão configuradas de uma forma que estão relacionadas com o próprio grupo social a que pertencem. $\mathrm{E}$ ainda, segundo a mesma autora, as relações sociais e culturais dos grupos são marcantes na formação destas memórias coletivas. Se a memória e a identidade são um processo, também é importante perceber as formas do grupo se relacionarem e como vão formatando a ideia de comunidade.

Além disso, ARAGÃO \& MALAGODI (2006) apontam que o patrimônio cultural também é importante para a sustentabilidade dos assentamentos, visto que as possibilidades de cultivos não são infinitas ao se apoiarem em saberes locais. Neste sentido, o caráter sócio cultural e educacional é visto como sendo de suma 
importância para a análise das potencialidades de cada assentamento, dado que as diferenças regionais devem ser devidamente observadas para que haja êxito no seu processo de implantação (FERRANTE, 2006).

\section{CONCLUSÕES}

Em síntese, podemos concluir mediante análise da situação sociocultural e educacional dos PA's Maravilha e Vale do Moju, que este trabalho realizado junto às famílias assentadas, possibilitou constatar que o conhecimento da trajetória de vida que envolve aspectos sociais, culturais e educacionais dos agricultores assentados é fundamental para o estabelecimento de estratégias de desenvolvimento dos assentamentos em questão, visto que cada família detem um patrimônio sociocultural específico, relacionado à sua história de vida, o que garante conhecimentos e saberes intrínsecos, que podem impulsionar novas dinâmicas de desenvolvimento social nos PA's.

Além do mais, houve consenso entre as famílias sobre a necessidade de construir um ambiente mais saudável e evolutivo destes aspectos para as famílias residentes, considerando a importância da organização social das comunidades como uma alternativa para o progresso dentro dos centros comunitários.

\section{AGRADECIMENTOS}

Aos agricultores assentados da Reforma Agrária nos Projetos de Assentamento Maravilha e Vale do Moju, sem a participação dos jovens, homens e mulheres moradores (as) nestes PA's este trabalho não teria sido construído, assim como da colaboração dos membros da associação destes PA's.

\section{REFERÊNCIAS}

ALVES, R. J. M.; ROCHA, L. C. F.; PONTES, A. N.; COSTA, M. S. S.; CAMPOS, P. S. S. Estudo socioeconômico de comunidades da área do polo industrial de Barcarena, Pará, Brasil. Enciclopédia Biosfera, Goiânia, v. 11, n. 21, p. 3125-3136, 2015.

ALVES, R. J. M.; PONTES, A. N.; GUTJAHR, A. L. N. Caracterização Socioeconômica de Comunidades Rurais Amazônicas do Estado do Pará, Brasil. Observatorio de la economía latino-americana. Revista eumednet. Brasil, Julio, 2015.

BORIN, E. C. P.; LIMA, F. G. F. Uma abordagem do associativismo: o estudo de caso da ranicultura em Guaratiba/RJ. Polêm!Ca, Rio de Janeiro, v. 12, n. 4, p. 740749, 2013.

BRASIL, Ministério da Agricultura Pecuária e Abastecimento. Secretaria de Desenvolvimento Agropecuário e Cooperativismo. Cooperativismo. Brasília, 2012. $50 \mathrm{p}$.

BRASIL, Ministério da Saúde. Melhoria contínua da qualidade na atenção primária à saúde. Brasília, DF, 2010, 141p. 
CAMARANO, A. A. Envelhecimento da população brasileira: uma contribuição demográfica. Brasília: IPEA, 2002. (Texto para discussão, 858).

FERREIRA, F. de J.; BRANDÃO, E. C. Educação do campo: um olhar histórico, uma realidade concreta. Revista Eletrônica de Educação. Ano V. №09, jul./dez. 2011.

FRANCO, C. A.; LIMA, D. de S. Dinâmica populacional dos projetos de assentamentos da regional do Baixo Acre. SOBER XLVI CONGRESSO DA SOCIEDADE BRASILEIRA DE ECONOMIA, ADMINISTRAÇÃO E SOCIOLOGIA RURAL. Rio Branco - Acre, 20 a 23 de julho de 2008.

FRIGOTTO, G. Projeto societário contra-hegemônico e educação do campo; desafios de conteúdo, método e forma. In: Munarin Antônio, Beltrame Sônia, Conte Soraya Franzoni e Peixer Isabel (orgs). Educação do campo: reflexões e perspectivas. Florianópolis: Insular, 2 ed., 2011.

INCRA. Relatório Agronômico de Fiscalização - Imóvel Rural com Denominação Especial Fazenda Vale do Moju. Outubro de 2001.

MANUAL DE SANEAMENTO RURAL. CISAM / AMVAP. Novembro de 2006. Disponível $<$ http://www.cbn.org.br/redemi/images/download/saude/manual_saneamento_rural(C ISAM).pdf> Acesso em 03 de maio de 2016.

MOREIRA, E. M. Práticas da pós-graduação Direitos Sociais do campo: Fortalecendo a relação ensino-pesquisa-extensão. Revista Insurgência, Brasília, ano 1, v.1, n.1, jan./jun. 2015.

NABOZNY, A.; RODRIGUES, D. Associativismo rural: avanços e retrocessos no desenvolvimento sócio espacial na comunidade de Guamirim-Irati/PR. Campoterritório: Revista de Geografia Agrária, Uberlândia, v. 6, n. 12, p. 264-286, 2011.

NETO, L. B.; BEZERRA, M. C. S. Aspectos da educação rural no Brasil, frente aos desafios educacionais propostos pelo MST. Revista HISTEDBR On-line, Campinas, n.26, p.130-143, jun. 2007.

PESSOA, E.A. A Constituição Federal e os Direitos Sociais Básicos ao Cidadão Brasileiro. Disponível em: http://www.ambitojuridico.com.br/site/?n_link=revista_artigos_leitura\&artigo_id=9623\&revista_caderno $=9$. Acesso em: 23 de fevereiro de 2016 .

PTDRS. Território da Cidadania Baixo Tocantins. 2011. Disponível em: $<$ http://sit.mda.gov.br/download/ptdrs/ptdrs_qua_territorio130.pdf. Acesso em: 13 de julho de 2015.

ROMERO, F. L. "Fazer artesanato para fazer a roça": práticas sociotécnicas na comunidade quilombola da Serra das Viúvas. Ciências Sociais Unisinos, São Leopoldo, v. 50, n. 3, p. 281-292, 2014. 
SANTOS JUNIOR, O. A. DOS; CHRISTOVÃO , A.C; NOVAES, P. R. Programa Interdisciplinar de Formação de Agentes Sociais e Conselheiros Municipais. Rio de Janeiro: Letra Capital: Observatório das Metrópoles: IPPUR/UFRJ, 2011. il. (Caderno didático).

SENAR - Serviço nacional de Aprendizagem Rural. Associações rurais: práticas asscociativas, características e formalização. Brasília: SENAR, 2011. 56p.: il.; $21 \mathrm{~cm}$. (Coleção SENAR; 153).

SILVA, A. F. da. A relação cidade-campo: como analisá-la? Natal-RN: Ed. Imagem, 1998.

SOUZA, M. L. O território: sobre espaço e poder, autonomia e desenvolvimento. In: CASTRO, I. E. GOMES, P. C. \& CORRÊA, R. L. (Org). Geografia: Conceitos e Temas. Rio de Janeiro: Bertand, 1995. P.77-116.

SCHLINDWEIN, V. de L. D. C. A desproteção social dos trabalhadores rurais nos acidentes de trabalho. Textos \& Contextos (Porto Alegre), v. 10, n. 1, p. 109 - 117, jan./jul. 2011.

TERCEIRO, A.; SILVA, J. J. S.; CORREIA, M. F. Caracterização da sociedade, economia e meio ambiente costeiro atuante à exploração dos manguezais no estado do Maranhão. Revista de Administração e Negócios da Amazônia, Porto Velho, v. 5, n. 3, p. 94-111, 2013.

VERDEJO, M. E. Diagnóstico Rural Participativo - Um Guia Prático (DRP). Brasília, março de 2006. Disponível em <file:///C:/Users/casa/Downloads/DRP.pdf> Acesso em 02 de maio de 2016.

WEIDUSCHADT, P. O lazer e a construção da identidade numa comunidade rural de descendentes germânicos em Pelotas. V. VI, n91/12. Pelotas, RS: Editora da UFPEL, 2009. 